and quality adjusted life years). A Colombian National Health System perspective (direct medical costs) was considered. Resource utilization was extracted from National Payment Manuals and databases of open access. Costs are expressed in Colombian Pesos (COP). Deterministic and probabilistic sensitivity analyses were performed.

Results Stent-retriever thrombectomy with Intravenous Tissue Plasminogen Activator (IV-tPA) was associated with better outcomes (4.38 life years gained and 2.96 quality adjusted life years) and savings of COP $\$ 1,824,733$ resulting in a dominant therapy over intravenous tissue plasminogen activator alone. A net monetary benefit of COP $\$ 66,005,604$ was obtained considering a willingness-to-pay threshold of COP $\$ 69,081,720$.

Discussion The results were consistent with a previously published cost-effectiveness analysis and reinforce the likeliness of the selection of stent-retriever mechanical thrombectomy plus intravenous tissue plasminogen activator over intravenous tissue plasminogen activator alone.

Conclusion Stent-retriever thrombectomy in combination with Intravenous Tissue Plasminogen Activator is a dominant alternative over intravenous tissue plasminogen activator alone (more effective and less costly) for the treatment of acute ischaemic stroke patients with large vessel occlusions in Colombia.

Disclosures B. Pabon: 2; C; Medtronic. J. Tellez: 5; C; Medtronic. J. Arcos: 5; C; Medtronic. P. Guijarro: 2; C; Medtronic. C. Diaz: None.

\section{P-019 ASPECTS DECAY CAUSING INELIGIBILITY FOR THROMBECTOMY IN PATIENTS TRANSFERRED TO A COMPREHENSIVE STROKE CENTER COVERING A LARGE GEOGRAPHIC AREA}

${ }^{1} S$ Ahmed*, ${ }^{2} \mathrm{E}$ Noyes, ${ }^{3} \mathrm{~K}$ Whelan, ${ }^{2} \mathrm{~B}$ Graham, ${ }^{2} \mathrm{G}$ Hunter, ${ }^{1} \mathrm{M}$ Kelly, ${ }^{1} \mathrm{~L}$ Peeling. ${ }^{1}$ Neurosurgery, University of Saskatchewan, Saskatoon, SK, Canada; ${ }^{2}$ Neurology, University of Saskatchewan, Saskatoon, SK, Canada; ${ }^{3}$ Saskatchewan Cerebrovascular Center, University of Saskatchewan, Saskatoon, SK, Canada

\subsection{6/neurintsurg-2019-SNIS.55}

Introduction Endovascular therapy has revolutionized acute stroke management associated with large vessel occlusion (LVO). The province of Saskatchewan currently has 8 primary stroke centers (PSC) and 1 comprehensive stroke center (CSC) spread over a large geographical area. Seventy three percent of the population lives outside the Saskatoon metropolitan area, which houses the province's single comprehensive stroke centre. Geography remains a significant barrier to providing endovascular therapy in a timely manner to eligible patients, knowing that the time to recanalization is a vital variable in clinical outcome. We aim to quantify the distance and time to transfer of patients to the CSC, and determine factors associated with clinically significant evolution of infarct during transfer.

Methods We completed a retrospective analysis of all acute stroke patients with LVOs who were transferred from PSCs to the CSC for possible endovascular therapy in Saskatchewan from July 2016 - July 2018. Along with patient, imaging, and outcome specific factors, detailed transfer data including modality, time, and distance were collected.

Results Forty-seven patients were identified as having had a LVO diagnosed at a PSC, with subsequent transfer to the
CSC for endovascular therapy. The average age was 70.6 years. Of these patients, 13 (28\%) underwent EVT, while 34 patients did not: 7 (15\%) had clinical improvement, 12 (25\%) had vessel recanalization on repeat CTA, and 15 (32\%) had ASPECTS decay leading to EVT ineligibility. Distance to the PSC and distance from PSC to CSC were the most significant contributors to ASPECTS decay.

Conclusion Rates of ineligibility due to ASPECTS decay were similar to those found in other regional data, despite significantly greater distances. Since the large geographic area covered by the CSC leads to a significant cost burden associated with transfers, we aim to optimize transfer protocols to better serve the outlying areas.

Disclosures S. Ahmed: None. E. Noyes: None. K. Whelan: None. B. Graham: None. G. Hunter: None. M. Kelly: None. L. Peeling: None.

\section{P-020 THE USE OF HF-OCT IN THE PREDICTION OF ANEURYSM OCCLUSION}

${ }^{1} \mathrm{R}$ King ${ }^{*},{ }^{1} \mathrm{M}$ Marosfoi, ${ }^{2} \mathrm{~J}$ Caroff, ${ }^{1} \mathrm{G}$ Ughi, ${ }^{1} \mathrm{D}$ Groth, ${ }^{1} \mathrm{M}$ Gounis, ${ }^{1} \mathrm{~A}$ Puri. ${ }^{1}$ Radiology, University of Massachusetts, Worcester, MA; ${ }^{2}$ Interventional Neuroradiology, Bicetre Hospital, Le Kremlin-Bicêtre, France

\subsection{6/neurintsurg-2019-SNIS.56}

Introduction The development of High Frequency $\mathrm{OCT}^{1}$ (HFOCT) allows for higher resolution intra-arterial imaging, such that vascular remodeling in response to stents and next generation intrasaccular devices (NGID) can be interrogated. We hypothesize that imperfections or gaps in the neck coverage of an aneurysm after treatment with a NGID will be predictive of failed aneurysm occlusion.

Materials and methods Two aneurysms were made in each of six dogs, one sidewall aneurysm on the distal right common carotid artery (CCA), and a bifurcation aneurysm proximally at the apex of an anastomosis between the left and right CCAs. One aneurysm was excluded due to thrombosis at the time of treatment. Each aneurysm was treated with either detachable coils, or NGID, with a 7:4 randomization NGID: COIL. At implant, HF-OCT was obtained after each aneurysm was successfully packed. At 180 days, animals were assessed for final aneurysm occlusion by DSA. Separately, the HF-OCT data sets were automatically segmented such that gaps in the coverage of the aneurysm neck could be identified and used to predict if the aneurysm occlusion at 180 days.

Results The overall rate of occlusion was not seen to be different between the NGID and COIL group $(p=0.45)$ on the Raymond-Roy scale. ${ }^{2}$ All of the NGID constructs were successfully segmented, and the associated larges gap in the neck coverage for each was determined. A gap in the NGID construct at the level of the neck greater than $1 \mathrm{~mm}^{2}$ predicted failed aneurysm occlusion at 180-days ( $\mathrm{p}=0.047)$. This threshold correctly classified all aneurysms.

Conclusions HF-OCT allows not only for the imaging and segmentation of intra-arterial devices in vivo, but showed great potential as a robust diagnostic tool. Preliminary evidence collected in this study showed that HF-OCT can prognosticate aneurysm treatment success at the time of treatment.

\section{REFERENCES}

1. Stroke. 2018:Nov29:STROKEAHA118022315

2. Stroke. 2003;34(6):1398-1403. 


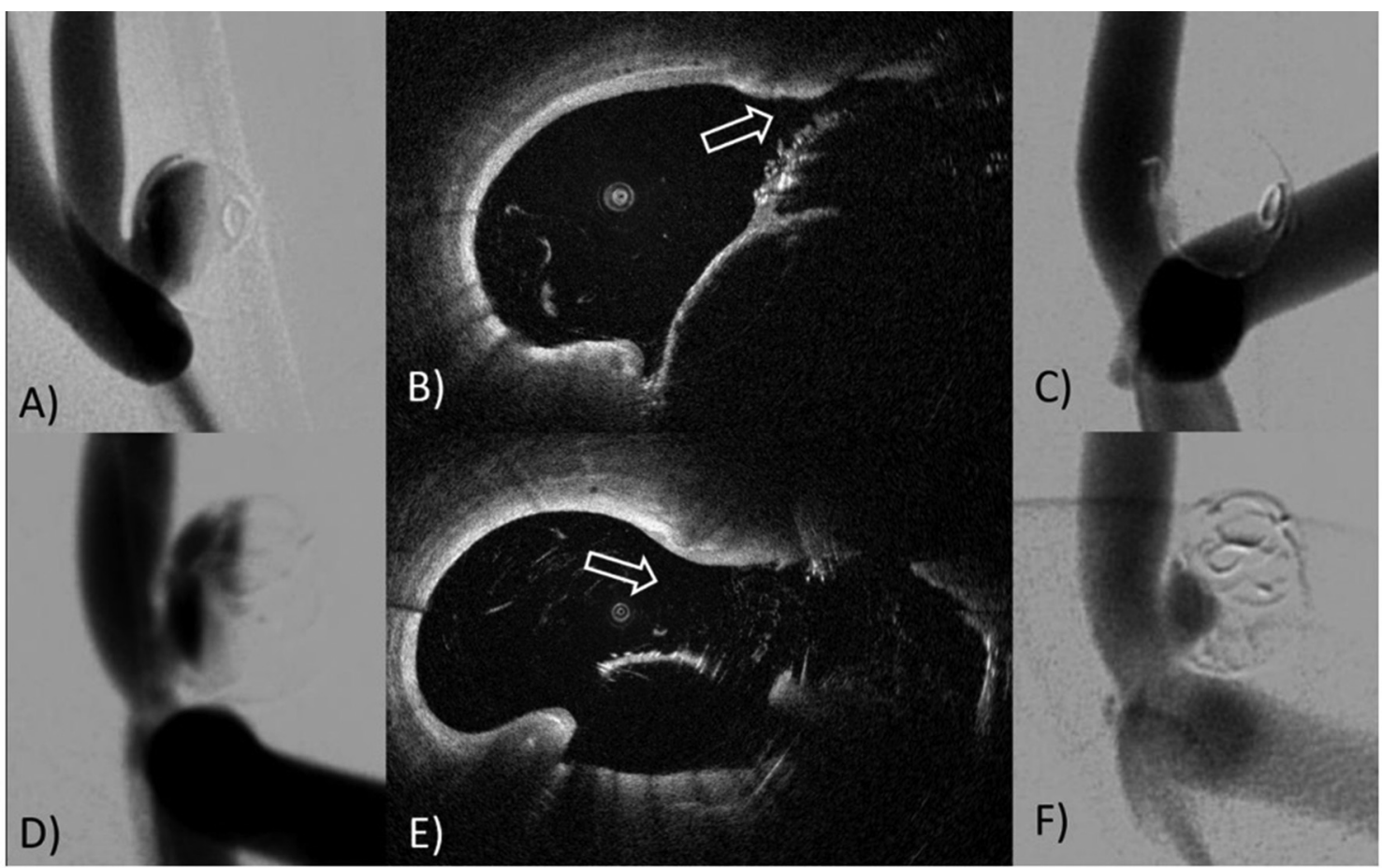

Abstract P-020 Figure 1 The upper panels show implant DSA (A), implant HF-OCT cross-sectional imaging, with the device visible between 1 and 6 o'clock (B), and 180-day final DSA (C), for an animal with a small gap in the construct (white arrow, B). The device successfully healed at 180-day DSA. The lower panels show implant DSA (D), implant HF-OCT cross-sectional imaging (aneurysm neck between 2 and 6 o'clock) (E), and 180-day DSA (F) for an animal with a large gap in the construct (white arrow, E). In this case, the device remained open at 180-day final DSA.

Abstract P-020 Table 1 largest coverage gap in the NGID construct as it compares to the implant and final DSA occlus

\begin{tabular}{lllll}
\hline $\begin{array}{l}\text { Animal } \\
\text { number }\end{array}$ & Location & $\begin{array}{l}\text { Implant } \\
\text { DSA score }\end{array}$ & $\begin{array}{l}\text { Largest coverage gap at } \\
\text { implant }\left(\mathbf{m m}^{2}\right)\end{array}$ & $\begin{array}{l}\text { 180-D DSA } \\
\text { outcome score }\end{array}$ \\
\hline Animal 2 & Bifurcation & 3 & 1.57 & 3 \\
Animal 3 & Bifurcation & 3 & 0.18 & 1 \\
Animal 4 & Sidewall & 2 & 0.55 & 1 \\
Animal 4 & Bifurcation & 3 & 1.30 & 3 \\
Animal 5 & Sidewall & 3 & 0.09 & 1 \\
Animal 6 & Sidewall & 3 & 0.08 & 1 \\
Animal 6 & Bifurcation & 3 & 0.12 & 1 \\
\hline
\end{tabular}

Disclosures R. King: None. M. Marosfoi: None. J. Caroff: None. G. Ughi: 4; C; Gentuity LLC. 5; C; Gentuity LLC. D. Groth: None. M. Gounis: None. A. Puri: None.

\section{P-021 COMFORT- COLOMBIAN MULTICENTER FLOW-DIVERTER OBSERVATIONAL RECONSTRUCTION TRIAL. LOCAL EXPERIENCE IN THE ENDOVASCULAR TREATMENT OF INTRACRANIAL ANEURYSMS WITH FRED STENT}

${ }^{1}$ B Pabon*, 'C Diaz, ${ }^{2} \mathrm{M}$ Fonseca, ${ }^{3} \mathrm{~N}$ Lobelo, ${ }^{4} \mathrm{~J}$ Holguin, ${ }^{1} \mathrm{~J}$ Mejia, ${ }^{1} \mathrm{O}$ Vargas, ${ }^{1} \mathrm{M}$ Patiño, ${ }^{1} \mathrm{~N}$ Serna. ${ }^{1}$ Neuroendovascular Surgery, Angioteam - Clinica del Norte, Medellin, Colombia; ${ }^{2}$ Neuroendovascular Surgery, unipamplona. medinorte, Cucuta, Colombia; ${ }^{3}$ Neuroendovascular Surgery, Clinica Colombia, bogota, Colombia; ${ }^{4}$ Neuroendovascular Surgery, Clinica Imbanaco, Cali, Colombia

10.1136/neurintsurg-2019-SNIS.57
Purpose Flow-diverting stents, such as the Flow Re-direction Endoluminal Device (FRED; MicroVention, Tustin, California, USA), have emerged as a novel means of treating complex intracranial aneurysms. This observational analysis of the initial Colombian experience provides insight into patient selection, technical challenges, clinical and radiographic outcomes, and complication rates after the use of FRED device for intracranial aneurysms.

Materials and methods Cases were compiled from 5 Colombian centers between March 2014 and April 2017. We performed a multicenter study evaluating patients with intracranial aneurysms treated with FRED. Technical success, morbidity and mortality were registered. Regarding safety, a well-defined variables included: spontaneous rupture of the FRED-treated aneurysm; spontaneous nonaneurysmal or distal intracranial hemorrhage (ICH); thrombo- embolic stroke; parent artery stenosis, and permanent cranial neuropathy.

Results During the defined study period, 252 patients with 268 aneurysms treated with FRED were included in this registry. Technical success stent deployment observed in all cases with exception of two cases where the operators decided to pull back the device and treated the aneurysms with other strategy. The mean aneurysm size was $12.4 \pm 5 \mathrm{~mm}$, and the median angiographic follow-up was 11.5 months. 81 aneurysms (30.2\%) were small, $132(49.2 \%)$ were large and 55 $(20.5 \%)$ were giant. The median clinical follow-up time was 16 months. The neurological morbidity rate was 7.5\% (19/ $252)$, and the neurological mortality rate was $2.3 \%(6 / 252)$. The combined neurological morbidity/mortality rate was $9.8 \%$. The most common adverse events were ischemic stroke $(5.9 \%, 15 / 252)$ and spontaneous ICH $(1.9 \%, 5 / 252)$. The complete occlusion rate at the last follow-up was $87.6 \%$ (92/ 105). 